\title{
Significance of Absorbing Fraction of Coating on Absorption Enhancement of Partially Coated Black Carbon Aerosols
}

\author{
Xiaolin Zhang ${ }^{1,2, *(\mathbb{D})}$, Yuanzhi Wang ${ }^{1,2}$, Yu Zhou ${ }^{1,2}$, Junyao Wang ${ }^{3}$ and Mao Mao ${ }^{1,3}$ \\ 1 Key Laboratory of Meteorological Disaster, Ministry of Education (KLME)/Key Laboratory for \\ Aerosol-Cloud-Precipitation of China Meteorological Administration, Nanjing University of Information \\ Science \& Technology, Nanjing 210044, China; 20201248029@nuist.edu.cn (Y.W.); \\ 20201248035@nuist.edu.cn (Y.Z.); mmao@nuist.edu.cn (M.M.) \\ 2 School of Atmospheric Physics, Nanjing University of Information Science \& Technology, \\ Nanjing 210044, China \\ 3 School of Atmosphere and Remote Sensing, Wuxi University, Wuxi 214105, China; wwjjyy000625@163.com \\ * Correspondence: xlnzhang@nuist.edu.cn
}

Citation: Zhang, X.; Wang, Y.; Zhou, Y.; Wang, J.; Mao, M. Significance of Absorbing Fraction of Coating on Absorption Enhancement of Partially Coated Black Carbon Aerosols. Atmosphere 2021, 12, 1422. https:// doi.org/10.3390/atmos12111422

Academic Editor: Angeliki Karanasiou

Received: 6 October 2021

Accepted: 25 October 2021

Published: 28 October 2021

Publisher's Note: MDPI stays neutral with regard to jurisdictional claims in published maps and institutional affiliations.

Copyright: (c) 2021 by the authors. Licensee MDPI, Basel, Switzerland. This article is an open access article distributed under the terms and conditions of the Creative Commons Attribution (CC BY) license (https:// creativecommons.org/licenses/by/ $4.0 /)$.

\begin{abstract}
Black carbon (BC), particularly internally mixed and aged BC, exerts a significant influence on the environment and climate. Black carbon coated by non-absorbing materials shows an enhancement of $\mathrm{BC}$ absorption, whereas absorptive coatings on $\mathrm{BC}$ can reduce the $\mathrm{BC}$ absorption enhancement. In this paper we use the multiple-sphere T-matrix method to accurately model the influence of the absorbing volume fraction of absorbing coatings on the reduction of the absorption enhancement of partially coated BC. The reduction of the absorption enhancement due to the absorbing coating exhibited a strong sensitivity to the absorbing volume fraction of the coating, and no reduction of $\mathrm{BC}$ absorption enhancement was seen for $\mathrm{BC}$ particles with non-absorbing coatings. We found that coatings with higher absorbing volume fraction, greater coated volume fraction of $\mathrm{BC}$, higher shell/core ratio, and larger coated BC particle size caused stronger reductions of the BC absorption enhancement, whereas the impact of the $\mathrm{BC}^{\prime}$ 's fractal dimension was negligible. Moreover, the sensitivity of the reduction of absorption enhancement resulting from the ratio of the absorbing coating shell to the BC core increased for coatings with higher absorbing volume fractions, higher coated volume fractions of BC, or larger particle sizes, although this effect was weaker than the sensitivities to size distribution, absorbing volume fraction of coating, and coated volume fraction of BC. Reductions in the absorption enhancements resulting from the absorbing coating for partially coated BC with various size distributions typically varied in the range of $0.0-0.24$ for thin coatings with shell/core ratio of 1.5 and between 0.0 and 0.43 for thick coatings with shell/core ratio of 2.7. In addition, we propose an empirical formula relating the reduction of $\mathrm{BC}$ absorption enhancement to the absorbing volume fraction of the coating, which could inform a quantitative understanding and further applications. Our study indicates the significance of the absorbing volume fraction of coatings on the absorption properties of BC.
\end{abstract}

Keywords: black carbon aerosol; absorption enhancement; coating; absorbing volume fraction of coating

\section{Introduction}

Aerosols in ambient air can interact with atmospheric radiation, and influence the climate and synoptic weather through the process of radiative transfer [1-5]. Among various aerosol constituents, carbonaceous aerosols (e.g., black carbon, BC) exert a profound influence on climate change and global energy balance due to the intense absorption and scattering of radiation [6]. As a byproduct of the incomplete combustion of fossil fuels, biomass burning, and biofuels, BC aerosols contribute significant positive radiative forcing at the top of the atmosphere and serve as a strong anthropogenic warming agent [7]. At present, the understanding of BC's radiative properties is still limited due to the aggregates' 
complex microphysics (e.g., morphology, mixing state), which make BC and organics some of the largest uncertainties in the assessment of aerosol radiative forcing [8].

Fresh BC particulates are commonly hydrophobic and externally mixed, whereas they become internally mixed with other aerosol constituents due to aging processes $[9,10]$. It is reported that this aging process occurs on a timescale from a few minutes to several days $[11,12]$ and is even faster in polluted atmospheric environments $[13,14]$. During the aging process, $\mathrm{BC}$ can have water-soluble coating components, including condensations of nitrate, organics, and sulfate [15,16]; coagulations with preexisting aerosol species [17,18]; and heterogeneous reactions with gaseous oxidants $[19,20]$. Among BC coatings, an absorbing coating (named brown carbon) is a type of organic matter that can absorb radiation in ultraviolet and visible spectral regions [21]. Coatings on BC can significantly change $B C$ 's microphysical, optical, and radiative properties, which have been presented in multiple studies [22]. Coated BC tends to be a compact aggregate compared to fresh chainlike structures, and large aggregate fractal dimensions close to 3.0 have been observed [23]. The optics of $\mathrm{BC}$ (e.g., absorption) are altered after coating, and positive radiative forcing may be caused compared to the conditions of external mixing [24]. A few recent review papers have nicely summarized and highlighted the importance $B C$ coating materials and structures and the associated radiative effects on BC absorption [25-27].

Field experiments have indicated that a non-absorbing coating internally mixed with $\mathrm{BC}$ can significantly enhance BC absorption, although weak BC absorption enhancements have also been observed [28]. It has been reported that the mass ratio of non-BC components to $\mathrm{BC}$ within particles determines $\mathrm{BC}$ absorption enhancement, whereas no absorption enhancement has been reported for ratios lower than 1.5 [29]. Chakrabarty and Heinson [30] propose a scaling law to relate absorption enhancements to mass cross sections of absorption. A wavelength-dependent $\mathrm{BC}$ absorption enhancement with a value near 1.6 at near-IR wavelength was observed by You et al. [31]. Fresh BC from combustion showed a BC absorption enhancement of 1.4 whilst it reached about 3.0 for aged $\mathrm{BC}$ over a rural area in north China [32]. A study in Jinan, China reported an average BC absorption enhancement of 2.07, with diurnal variation patterns showing low and high values in the morning and afternoon, respectively [33]. In addition to field observations, numerical investigations related to the absorption of coated $\mathrm{BC}$ have also been carried out. Coated $\mathrm{BC}$ absorption impacted by aggregate morphology and internal mixing with the discrete dipole approximation is studied in Scarnato et al. [34]. Dong et al. [35] simulated aged BC with irregular sulfate coating and numerically investigated the absorption of coated $\mathrm{BC}$ as influenced by its morphology. He et al. [36] developed a model for BC aging to simulate the absorption enhancements of $\mathrm{BC}$ at different monodisperse sizes, and found that $\mathrm{BC}$ absorption enhancements varied with time. Black carbon absorption enhancements resulting from non-absorbing coatings influenced by detailed particle microphysics have been reported, and the significance of the coated volume fraction of $\mathrm{BC}$ on the determination of BC absorption enhancement has been emphasized [37,38].

While the absorption enhancement of $\mathrm{BC}$ with non-absorptive coatings has become clearer, the influence of absorbing coatings on BC absorption enhancement is still an open question. Some recent ambient experiments evaluating absorption enhancement have tried to eliminate both inorganic and organic coatings on BC particles; high absorption enhancement values of approximately 3.0 could be observed $[32,33]$. Nonetheless, these measured absorption enhancements may be overestimated, as organic coatings may include brown carbon [39], and the absorbing coating contributes to the overall absorption properties of coated BC aerosols. Luo et al. [40] numerically studied the impact of brown coatings on the absorption enhancement of fully encapsulated $\mathrm{BC}$ particles. The observations showed that aged $\mathrm{BC}$ aerosols commonly had fully coated, externally attached, and partially coated morphologies [41,42]. Although partial coating is also a significant mixing state of aged BC in the ambient atmosphere, studies on the absorption enhancement of partially coated BC as influenced by absorbing coatings are generally limited. Meanwhile, the coatings of BC 
may be a mixture of both non-absorbing and absorbing species, and the impact of these mixed coatings on $\mathrm{BC}$ absorption enhancement still needs more investigation.

Here, the absorption properties of BC particles partially coated with mixed coatings, and the reductions of absorption enhancement due to absorbing coatings, are systematically investigated based on current understandings. The absorption of coated BC aggregates is exactly calculated using a multiple-sphere T-matrix method (MSTM). The aim is to study the effect of the absorbing volume fraction of coatings on the reduction of absorption enhancement of partially coated $\mathrm{BC}$ due to the absorbing coating, which hopefully benefits our understanding of this subject and informs further applications in radiative transfer and aerosol-climate models.

\section{Materials and Methods}

Fresh BC aerosols generally show loose cluster-like aggregate structures with many small spherical monomers with similar sizes [43]. The fractal aggregate model has been successfully employed to describe these BC geometries on the basis of a mathematical scaling law following [44]:

$$
\begin{aligned}
& N=\mathrm{k}_{0}\left(\frac{R_{g}}{a}\right)^{D_{f}}, \\
& R_{g}=\sqrt{\frac{1}{N} \sum_{i=1}^{N} r_{i}^{2},}
\end{aligned}
$$

where the fractal prefactor of an aggregate $\left(\mathrm{k}_{0}\right)$, monomer number $(N)$, fractal dimension $\left(D_{f}\right)$, and monomer radius $(a)$ construct its structure. $r_{i}$ is the distance between the center of mass and the $i$ th monomer, while $R_{g}$ is the radius of gyration, representing the aggregate's total spatial size. Black carbon aerosols can be coated with other species (e.g., organics, sulfate) after being emitted into the atmosphere, and become aged quickly [13]. After being coated, chain-like BC structures can collapse into compact aggregates, and their radiative properties may be substantially altered [23]. It has been documented that the fractal dimensions of coated BC aggregates can be near 3, while fresh $B C$ generally shows fractal dimensions less than 2 [23]. The mixing-state observations show that coated $B C$ particles mainly exhibit three morphologies: fully coated, externally attached, and partially coated $[41,42]$. The coated volume fraction of $\mathrm{BC}(F)$ is used to describe the morphologies of coated $\mathrm{BC}$, and it is defined as:

$$
F=\frac{V_{B C} \text { within coating }}{V_{B C}},
$$

where $V_{B C}$ within coating indicates the volume of $\mathrm{BC}$ within a given coating and $V_{B C}$ is the overall volume, including the $\mathrm{BC}$ both in and outside its coating [38]. Based on this microphysical parameter, $F=0,0<F<1$, and $F=1$ correspond to externally attached, partially coated, and fully coated $\mathrm{BC}$ aerosols, respectively.

This study followed the BC model developed by Zhang et al. [38], and spherical coatings were considered for partially coated $\mathrm{BC}$ aggregates with no overlapping of monomers, as portrayed in Figure 1. It should be noted that some monomers of BC were slightly moved to avoid overlaps whereas the inner and outer parts of the aggregate were still in point contact. We considered shell/core ratios $D_{P} / D_{\mathcal{c}}$ (volume equivalent diameter of a particle divided by diameter of the $\mathrm{BC}$ core) in the range of 1.1-2.7 based on observations in other works $[45,46]$. Black carbon aggregates were generated with a tunable algorithm of monomer-cluster aggregation developed by Skorupski et al. [47]. The $\mathrm{k}_{0}$ of BC aerosols was assumed to be 1.2 [44], and $D_{f}$ values were considered as 1.8 and 2.8, describing loose and compact morphologies of BC, respectively [48]. This study followed the method in Zhang et al. [38] and considered an N of 200, as BC particles are mostly observed in accumulation mode. Table 1 summarizes the BC microphysical parameters used in the study, 
which were considered as representative on the basis of observations, and the physical meanings of the abbreviated parameters are listed in Table 2.

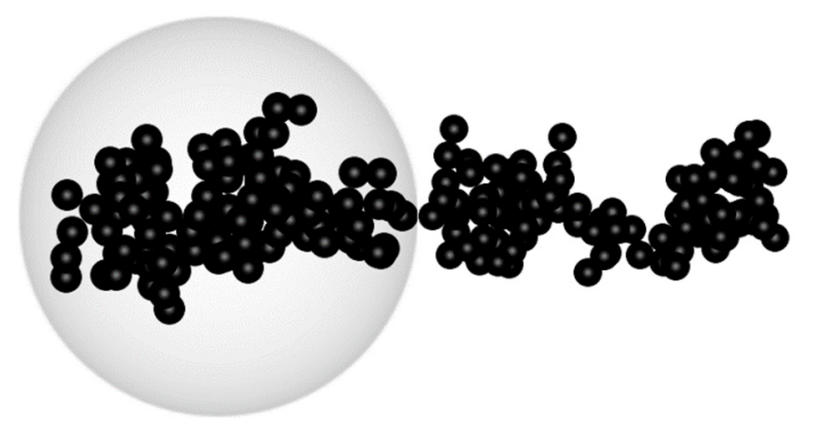

Figure 1. Modelled coated BC morphology. A fractal BC aggregate having 200 monomers is partially coated. The coated volume fraction of $\mathrm{BC}$ is 0.5 in this example.

Table 1. Microphysical parameters for coated BC particles.

\begin{tabular}{|c|c|c|}
\hline \multicolumn{2}{|c|}{ Parameters } & Used Values \\
\hline \multicolumn{2}{|c|}{$D_{f}$ of BC } & $1.8,2.8$ \\
\hline \multirow{2}{*}{\multicolumn{2}{|c|}{$\begin{array}{c}D_{p} / D_{c} \\
F\end{array}$}} & $1.1,1.5,1.9,2.3,2.7$ \\
\hline & & $0.01,0.25,0.5,0.75,0.99$ \\
\hline \multirow{2}{*}{ Size distribution } & $r_{g}, \mu \mathrm{m}$ & $0.075(0.05-0.15)$ \\
\hline & $\sigma_{g}$ & 1.59 \\
\hline
\end{tabular}

Table 2. Abbreviated parameters for coated BC particles.

\begin{tabular}{cc}
\hline Abbreviated Parameters & Meaning \\
\hline$D_{f}$ & Fractal dimension \\
$D_{p} / D_{c}$ & Shell/core ratio \\
$F$ & Coated volume fraction of BC \\
$f$ & Absorbing volume fraction of coating \\
\hline
\end{tabular}

Given the constructed model of aged BC, we applied the MSTM [49] to calculate the random-orientation absorption properties of $\mathrm{BC}$. This study considered the ensembles of coated $\mathrm{BC}$ with a lognormal size distribution in the form of

$$
\mathrm{n}(r)=\frac{1}{\sqrt{2 \pi} r \ln \left(\sigma_{g}\right)} \exp \left[-\left(\frac{\ln (r)-\ln \left(r_{g}\right)}{\sqrt{2} \ln \left(\sigma_{g}\right)}\right)^{2}\right],
$$

where $r_{g}$ denotes the geometric radius of coated $\mathrm{BC}$, while $\sigma_{g}$ is the standard deviation. We considered an $r_{g}$ of $0.075 \mu \mathrm{m}$ [50] and a $\sigma_{g}$ of 1.59 [51,52]. The absorption cross section $\left(C_{a b s}\right)$ of coated BC with this size distribution was obtained using

$$
\left\langle C_{a b s}\right\rangle=\int_{r_{\min }}^{r_{\max }} C_{a b s}(r) n(r) d(r) .
$$

The radius was considered in a range from $0.05 \mu \mathrm{m}$ to $0.5 \mu \mathrm{m}$, and a linearly equidistant radius interval with value of $0.005 \mu \mathrm{m}$ was used for averaging.

We modeled BC aggregates coated by organics, and organic coatings in ambient air may contain absorbing organics in addition to non-absorbing coatings. The absorbing volume fraction of coating $(f)$ was used to characterize the volume percentages of absorbing organics in the whole coatings, and it is calculated as:

$$
f=\frac{V_{\text {absorbing }}}{V_{\text {absorbing }}+V_{\text {non-absorbing }}},
$$


where $V_{\text {absorbing }}$ indicates the volume of absorbing coating, and $V_{\text {non-absorbing }}$ denotes the volume of non-absorptive coating. We utilized an effective refractive index for the coatings of organics that included both absorbing and non-absorbing components determined by $f$. The popular method of volume-weighted average was used to determine the effective refractive indices of this internally mixed coating, as it produced acceptable absorption results of coated $\mathrm{BC}$ particles in the accumulation mode [53]. We investigated the absorption properties of coated BC at $550 \mathrm{~nm}$ wavelength, and the refractive indices of absorbing organics, non-absorbing organics, and BC are $1.55-0.03 i$ [54], $1.55-0 i$ [55], and $1.85-0.71 i[56]$, respectively.

\section{Results and Discussion}

\subsection{Blocking Effect of Absorbing Coatings on BC Absorption Enhancement}

To investigate the effect of absorbing coatings on BC absorption enhancement, we considered the impacts of the scattering and absorption of absorbing coatings separately and its scattering acting as non-absorbing coatings on BC [52]. We compared the sum of the absorptions of absorbing coatings and $\mathrm{BC}$ with non-absorbing coatings to the absorption of BC with absorbing coatings alone. The results of partially coated BC aerosols with a coating absorbing volume fraction of 0.5 are illustrated in Figure 2. The absorptions of partially coated BC particles were averaged using the aforementioned size distribution with $r_{g}=0.075 \mu \mathrm{m}$ and $\sigma_{g}=1.59$. As shown in Figure $2 \mathrm{a}-\mathrm{e}$, the absorption cross sections $C_{a b s}$ of partially coated $\mathrm{BC}$ with an absorbing volume fraction of coating $f$ of 0.5 were highly sensitive to the shell/core ratio $D_{p} / D_{c}$ and coated volume fraction of $\mathrm{BC} F$, and slightly sensitive to the $\mathrm{BC}$ fractal dimension. The $C_{a b s}$ of partially coated $\mathrm{BC}$ significantly decreased with increasing $D_{p} / D_{c}$, while it increased with increasing $F$. This indicates that a decrease of $D_{p} / D_{c}$ or an increase of $F$ would cause enhanced BC absorption. Zhang et al. indicated that absorption enhancements of aged BC are significantly influenced by particle microphysics such as $F$ and $D_{p} / D_{c}[37,38]$. Figure 2a-e also indicates that the absorption of coated BC with an $f$ of 0.5 was lower than the sum of the absorptions of its absorbing coating and BC coated with related non-absorbing materials. This implies that the absorbing coating exerts a blocking effect on BC absorption enhancement, and weakening the overall particle absorption.

The absorption differences between coated BC with $f$ of 0.5 and the sum of the absorptions of its absorbing coating and $\mathrm{BC}$ with a related non-absorbing coating are illustrated in Figure $2 \mathrm{f}-\mathrm{j}$. It is obvious that their absorption differences were sensitive to shell/core ratio, coated volume fraction of $\mathrm{BC}$, and $\mathrm{BC}$ fractal dimension. The differences of absorption caused by different $\mathrm{BC}$ fractal dimensions were generally small, and the differences became smaller at larger $D_{f}$. The absorption differences were strongly sensitive to $F$ and $D_{p} / D_{c}$, indicating high sensitivities of the blocking effect induced by the absorbing coating to the shell/core ratio and the coated volume fraction of $\mathrm{BC}$. With increased $F$ or decreased $D_{p} / D_{c}$, the absorption of coated BC with an $f$ of 0.5 increasingly differed from the sum of absorptions of absorbing coating and BC coated with non-absorbing materials. Similar to BC absorption enhancement, we use the following equation to quantitatively express the blocking effect provided by an absorbing coating:

$$
E_{b}=-\frac{\left\langle C_{\text {abs_coated }}\right\rangle-\left\langle C_{\text {abs_absorbing }}\right\rangle-\left\langle C_{\text {abs_nonabsorbing }}\right\rangle}{\left\langle C_{\text {abs_bare }}\right\rangle},
$$

where $\left\langle C_{a b s \_c o a t e d}\right\rangle,\left\langle C_{a b s \_a b s o r b i n g}\right\rangle,\left\langle C_{a b s \_n o n a b s o r b i n g}\right\rangle$, and $\left\langle C_{a b s \_b a r e}\right\rangle$ are the absorptions of $\mathrm{BC}$ with an absorbing coating, the absorbing shell itself, $\mathrm{BC}$ coated with a non-absorbing coating, and bare $\mathrm{BC}$, respectively [40]. The $E_{b}$ indicates the reduction of $\mathrm{BC}$ absorption enhancement due to the blocking effect induced by an absorbing coating. An $E_{b}$ of zero implies no reduction in absorption enhancement, while there is full reduction (i.e., no absorption enhancement) if $E_{b}$ is equal to -1.0. Our study models more realistic BC geome- 
tries, whereas core/shell models consider that spheres may shield part of the absorbing mass and thus reduce the observed absorption cross sections [26].

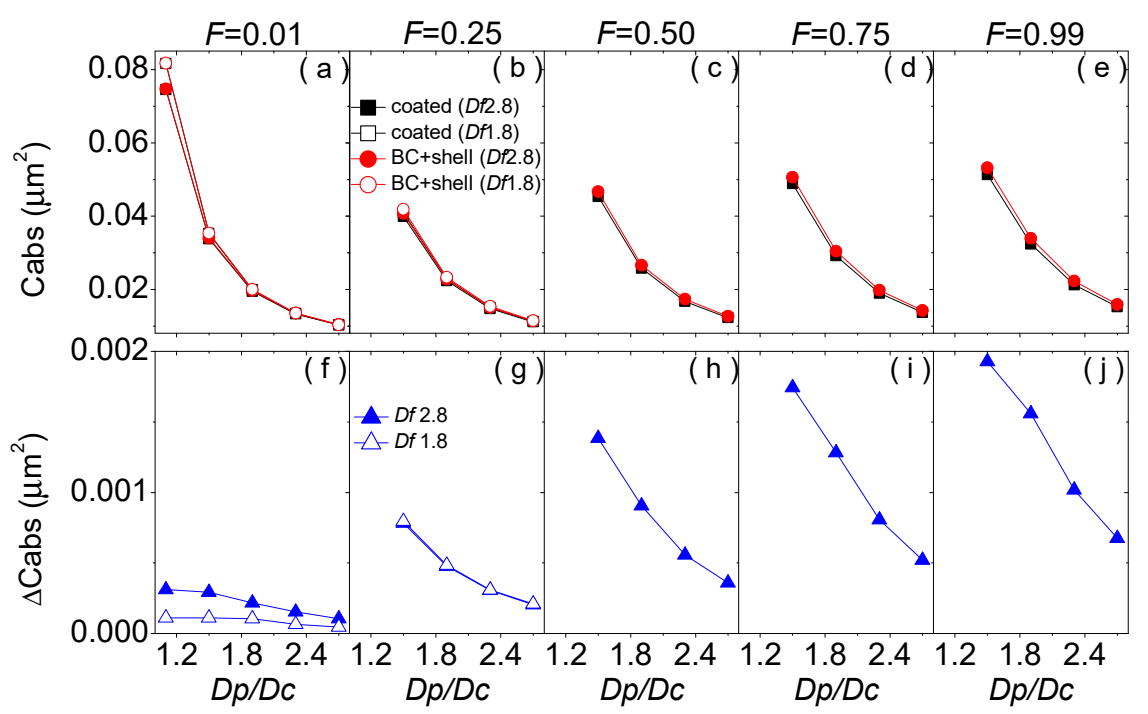

Figure 2. The absorption cross sections of BC partially coated by organics with an absorbing volume fraction of coating of 0.5 as a function of shell/core ratio $(D p / D c)$ at $550 \mathrm{~nm}$. The sums of absorption cross sections of absorbing coating and $\mathrm{BC}$ with a non-absorbing coating are compared to the absorptions of partially coated BC (top row), and their absorption differences are also shown (bottom row). Five coated volume fractions of BC $(F)$ being $0.01,0.25,0.5,0.75$ and 0.99 are shown from left to right. Open and solid symbols denote BC fractal dimensions of 1.8 and 2.8 , respectively. Black squares indicate the absorptions of partially coated BC with a coating absorbing volume fraction of 0.5. Red circles indicate the sums of the absorptions of absorbing coating and BC with a related non-absorbing coating. Blue triangles represent their absorption differences.

Figure 3 illustrates results regarding the $E_{b}$ partially coated BC with the aforementioned size distribution for different shell/core ratio and coated volume fraction of $\mathrm{BC}$, where $\mathrm{BC}$ aggregates with a $D_{f}$ of 2.8 and $f$ of 0.5 are considered. Figure 3 clearly shows that the $E_{b}$ of partially coated $\mathrm{BC}$ was highly sensitive to $F$ and $D_{p} / D_{c}$, and had a large variation. For $F$ near 0.0 , the $E_{b}$ of coated $\mathrm{BC}$ with $f$ of 0.5 exhibited weak variations with changing $D_{p} / D_{c}$ in the range of $0.003-0.019$. As $F$ increased, the $E_{b}$ of coated BC was more sensitive to $D_{p} / D_{c}$ and its value became larger. With $F$ close to 1.0, the $E_{b}$ of coated BC with an $f$ of 0.5 showed large values between 0.06 and 0.12 . For fixed $f$ and BC $D_{f}$, the $E_{b}$ increased as $F$ or $D_{p} / D_{c}$ increased. This indicates that a higher percentage of BC coated with a coating or a higher volume of coating leads to greater reductions in the absorption enhancement resulting from the blocking effect of the absorbing coating. Generally, these reductions were strongly sensitive to shell/core ratio and coated volume fraction of $\mathrm{BC}$. Meanwhile, with increasing coated volume fraction of $B C$, the sensitivity to shell/core ratio increased. 


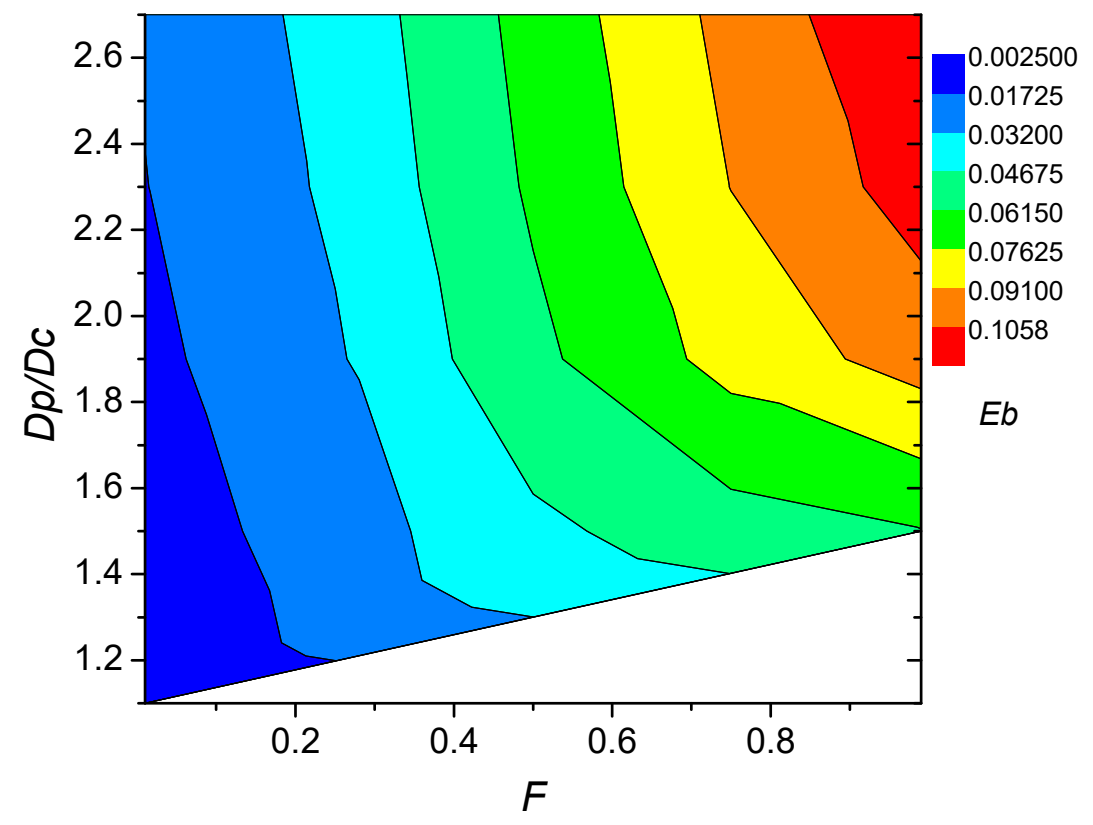

Figure 3. Absorption enhancement of $\mathrm{BC}$ reduced by the blocking effect of absorbing coating $\left(E_{b}\right)$ with an absorbing volume fraction of coating of 0.5 at $550 \mathrm{~nm}$. A BC fractal dimension of 2.8 and $\log$-normal size distribution with $r_{g}$ of $0.075 \mu \mathrm{m}$ and $\sigma_{g}$ of 1.59 are considered.

\subsection{Influence of Coating Absorbing Volume Fraction on Blocking Effect}

Figure 4 depicts the $E_{b}$ of partially coated $\mathrm{BC}$ as functions of $D_{p} / D_{c}$ and $f$ for different $F$. The aforementioned size distribution with $r_{g}=0.075 \mu \mathrm{m}$ and $\sigma_{g}=1.59$, and a BC $D_{f}$ of 2.8 are considered. The $E_{b}$ was strongly sensitive to $f$, and its sensitivity to $f$ was higher than that to $D_{p} / D_{c}$. The $E_{b}$ increased as $f$ increased, indicating that a higher coating absorption more strongly reduces the $\mathrm{BC}$ absorption enhancement with a stronger blocking effect. For BC with $f=0.0$, the $E_{b}$ of partially coated $\mathrm{BC}$ was zero, implying the absence of a blocking effect. Nevertheless, as $f$ increased to 1.0 , the $E_{b}$ increased significantly and exhibited values of $0.01-0.04,0.08-0.13$, and $0.12-0.23$ for partially coated BC with $F$ of 0.01 , 0.5 , and 0.99 , respectively. For $F$ values of $0.01,0.5$, and 0.99 , the $E_{b}$ values of thinly coated BC with $D_{p} / D_{c}=1.5$ were $0.0-0.02,0.0-0.08$, and $0.0-0.12$, respectively, whereas for thick coatings, the $E_{b}$ of coated $\mathrm{BC}$ became more sensitive to $f$ with wider variations. Moreover, for a fixed $D_{p} / D_{c}$, the $E_{b}$ of partially coated BC was more sensitive to $f$ at higher $F$ values. Meanwhile, for a fixed $F$, the $E_{b}$ of partially coated $\mathrm{BC}$ showed stronger sensitivity to $D_{p} / D_{c}$ at higher $f$.

To compare the $E_{b}$ sensitivities to $f$ with those to $F$, Figure 5 shows the $E_{b}$ of partially coated BC $\left(D_{f}=2.8\right)$ with the aforementioned size distribution as functions of $f$ and $F$ for different shell/core ratios. For $D_{P} / D_{c}$ values of 1.5, 1.9, 2.3, and 2.7, the $E_{b}$ values of partially coated $\mathrm{BC}$ with all possible coating structures were in the ranges of $0.0-0.12$, $0.0-0.19,0.0-0.21$, and $0.0-0.23$, respectively. It is obvious that the sensitivity of the $E_{b}$ to $f$ was similar to that to $F$. For a fixed $F$, the sensitivity of the $E_{b}$ to $f$ became higher as $D_{p} / D_{c}$ increased. Furthermore, for a fixed $D_{p} / D_{c}$ value, the sensitivity of the $E_{b}$ of partially coated $\mathrm{BC}$ to $F$ was higher at higher $f$. To summarize the results displayed in Figures 4 and 5, the reductions in the absorption enhancements of partially coated BC as a result of the blocking effect of coatings were very sensitive to $f, F$, and $D_{p} / D_{c}$, and the sensitivities to $f$ and $F$ were stronger than those to $D_{p} / D_{c}$. Meanwhile, the sensitivity of the reduction of absorption enhancement of partially coated $\mathrm{BC}$ to $D_{p} / D_{c}$ became stronger as $f$ and $F$ increased. 


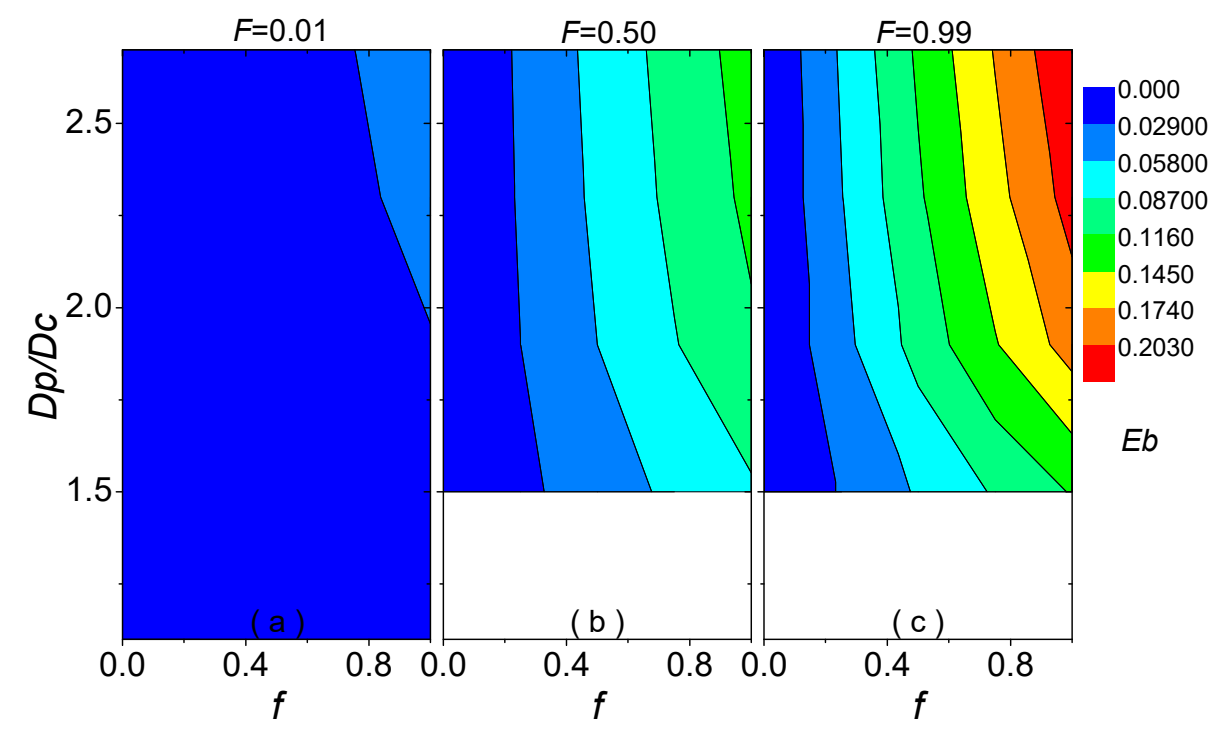

Figure 4. Absorption enhancement of $\mathrm{BC}$ reduced by the blocking effect of absorbing coating $\left(E_{b}\right)$ as functions of coating absorbing volume fraction $(f)$ and shell/core ratio $(D p / D c)$. Coated volume fractions of BC with values of $0.01,0.50$, and 0.99 are shown from left to right. A BC fractal dimension of 2.8 and log-normal size distribution with $r_{g}$ of $0.075 \mu \mathrm{m}$ and $\sigma_{\mathrm{g}}$ of 1.59 are considered.
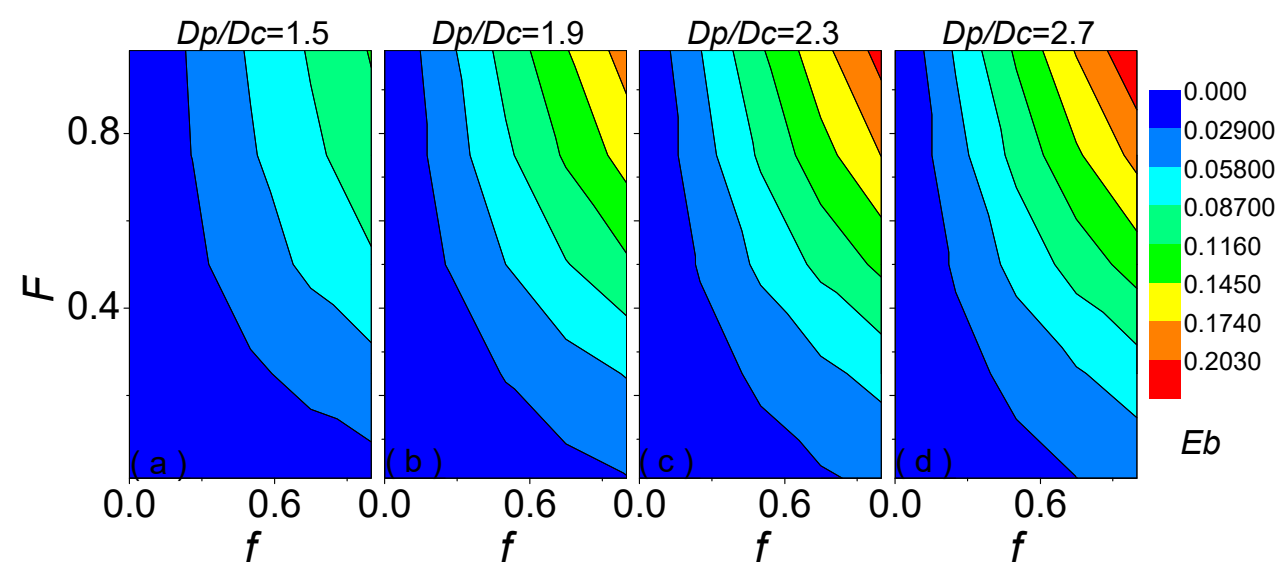

Figure 5. Absorption enhancement of $\mathrm{BC}$ reduced by the blocking effect of the absorbing coating $\left(E_{b}\right)$ as functions of the coated volume fraction of $\mathrm{BC}(F)$ and the coating absorbing volume fraction $(f)$. Four shell/core ratios of 1.5, 1.9, 2.3, and 2.7 are shown from left to right. A BC fractal dimension of 2.8 and log-normal size distribution with $r_{g}$ of $0.075 \mu \mathrm{m}$ and $\sigma_{g}$ of 1.59 are considered.

The results discussed above consider coated BC with a fixed particle size distribution, and the impact of size distribution on the reductions in the absorption enhancement of partially coated BC due to the blocking effect is given in the following. Figure 6 illustrates the $E_{b}$ of partially coated BC with various particle size distributions and $f$ values for different $F$. We assumed coated BC particles following lognormal distributions with $r_{g}$ between 0.05 and $0.15 \mu \mathrm{m}$ and $\sigma_{g}$ of 1.59. A BC fractal dimension of 2.8 and two shell/core ratios (1.5 and 2.7, representing thin and thick coatings, respectively) were considered. The $E_{b}$ of BC with an absorbing coating increased as $r_{g}$ increased, indicating that large particles of coated $\mathrm{BC}$ enhance the blocking effect due to the strong absorption of the coating. Meanwhile, the sensitivity of $E_{b}$ to $r_{g}$ was similar to its sensitivity to $f$. For fixed $F$ and $D_{p} / D_{c}$, large $f$ or $r_{g}$ led to high $E_{b}$, and partially coated BC with $f=0.0$ showed no blocking effect at all evaluated size distributions. With increasing $F$, the $E_{b}$ showed increased sensitivity to size distribution, and thinly coated BC with $D_{p} / D_{c}=1.5$ exhibited $E_{b}$ values in the ranges of $0.0-0.03,0.0-0.16$, and $0.0-0.24$ for $F$ of $0.01,0.5$, and 0.99 , respectively. The $E_{b}$ became more sensitive to particle size distribution for larger 
$D_{p} / D_{c}$, and wide $E_{b}$ variations in the ranges of $0.0-0.07,0.0-0.24$, and $0.0-0.43$ were seen for thickly coated $\mathrm{BC}\left(D_{p} / D_{c}=2.7\right)$ with $F$ of $0.01,0.5$, and 0.99 , respectively. In general, the $E_{b}$ of partially coated $\mathrm{BC}$ was sensitive to size distribution, and its sensitivity became stronger with increasing values of $F, D_{p} / D_{c}$, or $f$.

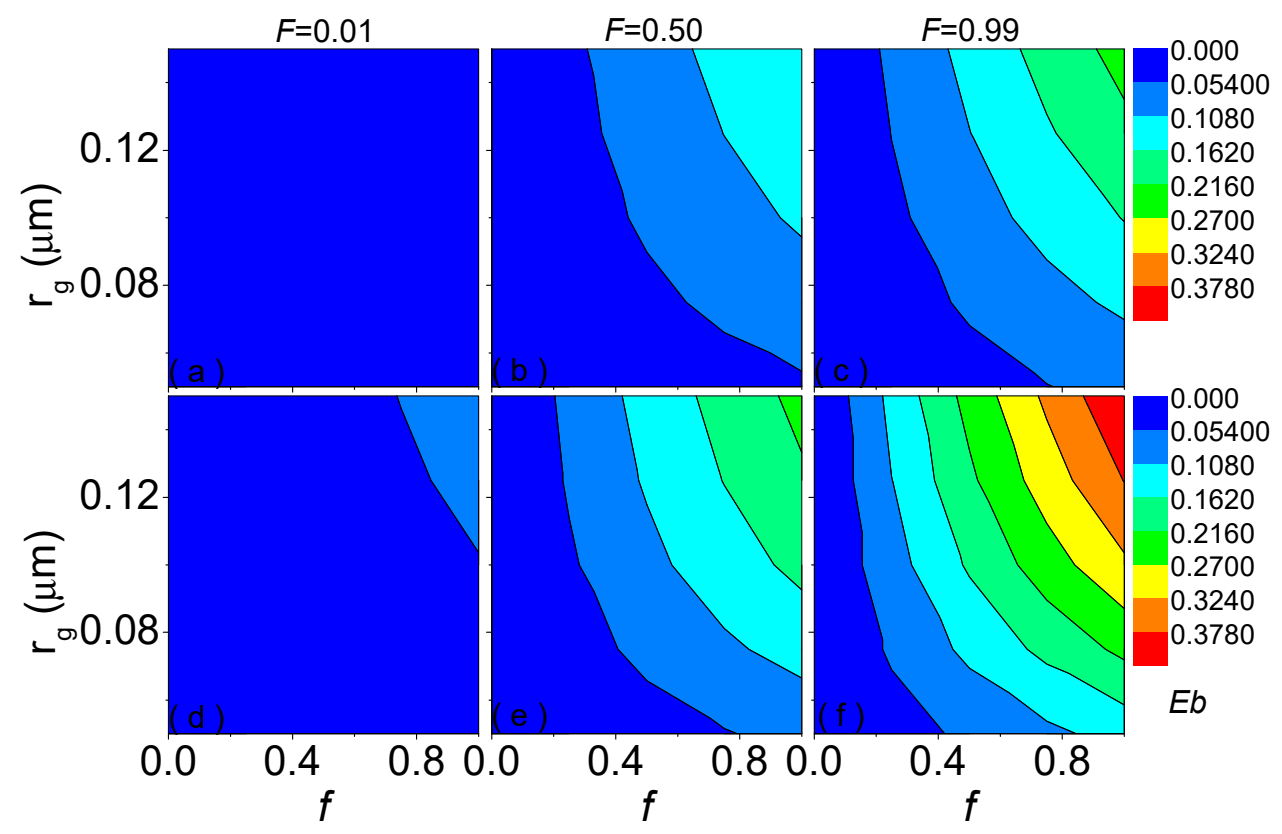

Figure 6. Absorption enhancement of $\mathrm{BC}$ reduced by of the blocking effect of the absorbing coating $\left(E_{b}\right)$ with different coating absorbing volume fractions $(f)$ and size distributions. Increasing coated volume fractions of BC $(0.01,0.50$, and 0.99$)$ are shown from left to right. Two shell/core ratios of 1.5 (top) and 2.7 (bottom) are considered. Geometric standard deviations $\left(\sigma_{g}\right)$ for applied log-normal distributions are 1.59.

\subsection{Empirical Formula for Blocking Effect Influenced by Absorbing Volume Fraction of Coating}

It is possible to establish the relation between $E_{b}$ and $f$ on the basis of the sensitivity analyses of the reduction of the absorption enhancements of partially coated BC due to the blocking effect, as influenced by $f$ and other microphysical parameters. The BC fractal dimension was not considered, as it showed a negligible impact on the $E_{b}$ of partially coated $\mathrm{BC}$ in the analyses. To facilitate practical applications, we considered a log-normal size distribution with $r_{g}=0.075 \mu \mathrm{m}$ and $\sigma_{g}=1.59$, which is intensively used in aerosol-climate models, and an empirical formula was assumed with the expression:

$$
E_{b}=E_{b 0}+k_{1} f \times F+k_{2} f \times F \times D_{p} / D_{c}
$$

where $k_{1}$ and $k_{2}$ are coefficients and indicate the significances of related influences on the $E_{b}$ of coated BC. These coefficients can be fitted with the $95 \%$ confidence range, and the $E_{b}$ of partially coated BC can be expressed as:

$$
E_{b}=0.00817+0.00495 f \times F+0.0877 f \times F \times D_{p} / D_{c} .
$$

The fitting coefficients were obtained with the lowest root-mean-square relative errors for all $E_{b}\left(R^{2}=0.97\right)$. The influences of $f$ and other particle microphysical parameters on $E_{b}$ were evidently affirmed by fitting the coefficients in Equation (9) for quantitative understanding, and large fitting coefficients indicate significant effects on $E_{b}$. To show the capability of the empirical formula in predicting the $E_{b}$ of partially coated BC, Figure 7 illustrates absolute $E_{b}$ differences between predictions obtained by Equation (9) and accurate numerical simulations. The predicted $E_{b}$ results agree well with accurate simulations, with differences all within 0.03 . This suggests that the simple empirical formula we proposed 
generates rather accurate estimations of $E_{b}$ for partially coated $\mathrm{BC}$ with representative size distributions, giving confidence on the accuracy of the empirical formula.

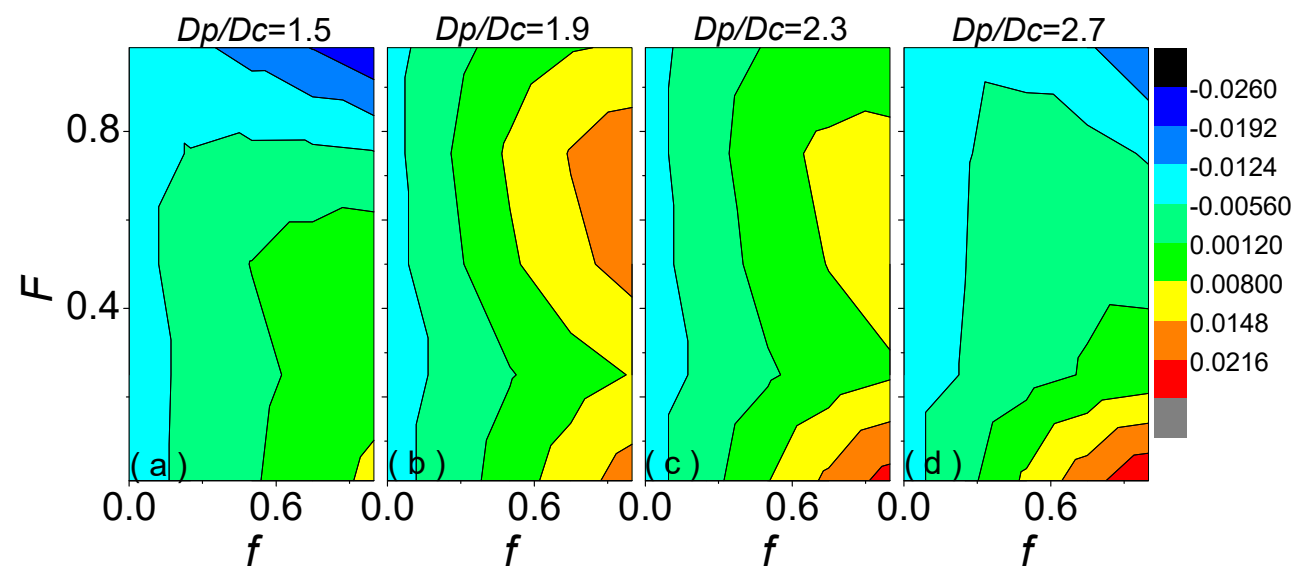

Figure 7. Absolute differences between the absorption enhancement of $\mathrm{BC}$ reduced by the blocking effect of an absorbing coating approximated with Equation (9) and those produced by exact numerical simulations. Four shell/core ratios of 1.5, 1.9, 2.3, and 2.7 are shown from left to right. A BC fractal dimension of 2.8 and log-normal size distribution with $r_{g}$ of $0.075 \mu \mathrm{m}$ and $\sigma_{g}$ of 1.59 are considered.

\section{Conclusions}

This study used an inhomogeneous model for the study of the absorption properties of partially coated BC particles computed using the MSTM, investigating the effect of the coating absorbing volume fraction on the reduction of $\mathrm{BC}$ absorption enhancement induced by blocking effects. Our results indicate that this reduction in $\mathrm{BC}$ absorption enhancement is strongly sensitive to the absorbing volume fraction of coating, and that there is no blocking effect for $\mathrm{BC}$ with a non-absorbing coating. Stronger blocking effects were seen for partially coated $\mathrm{BC}$ with a higher coating absorbing volume fraction, higher shell/core ratio, larger coated volume fraction of $\mathrm{BC}$, or larger particle size of coated $\mathrm{BC}$, whereas the fractal dimension of $\mathrm{BC}$ had a minor impact on blocking effect. The reductions of the absorption enhancements of partially coated $\mathrm{BC}$ with various size distributions typically varied in the range of $0.0-0.24$ for thin coatings $\left(D_{p} / D_{c}=1.5\right)$ and in the range of $0.0-0.43$ for thick coatings $\left(D_{p} / D_{c}=2.7\right)$. Furthermore, the sensitivities of the reductions of BC absorption enhancement to the absorbing volume fraction of coating, size distribution, and coated volume fraction of $\mathrm{BC}$ were higher than the sensitivity to shell/core ratio. The sensitivity to shell/core ratio became stronger for higher coated volume fraction of $\mathrm{BC}$, higher coating absorbing volume fraction, or larger particle size. Additionally, we presented an empirical formula relating $E_{b}$ to $f$, and it predicted the $E_{b}$ of partially coated BC well, with differences less than 0.03 for a typical log-normal size distribution with $r_{g}=0.075 \mu \mathrm{m}$ and $\sigma_{g}=1.59$. Overall, this study highlights the importance of the coating absorbing volume fraction on the reduction of $\mathrm{BC}$ absorption enhancement due to blocking effects, and compares the sensitivities of the blocking effect to particle microphysical parameters. With significant influences on $B C$ absorption properties-particularly a reduction of BC absorption enhancement due to blocking effects-there is an urgent need to consider absorbing coatings in $\mathrm{BC}$ observations and radiative simulations.

Author Contributions: Conceptualization, X.Z.; methodology, X.Z.; validation, X.Z.; investigation, X.Z., Y.W., Y.Z., J.W. and M.M.; data curation, X.Z.; writing-original draft preparation, X.Z.; writingreview and editing, X.Z.; visualization, X.Z. All authors have read and agreed to the published version of the manuscript.

Funding: Innovation and entrepreneurship training program for College Students in Jiangsu Province (202113982004Y). 
Institutional Review Board Statement: Not applicable.

Informed Consent Statement: Not applicable.

Data Availability Statement: Data available on request due to their robustness and restrictions on public sharing.

Acknowledgments: We acknowledge the source of the codes of MSTM 3.0 from Daniel W. Mackowski.

Conflicts of Interest: The authors declare no conflict of interest.

\section{References}

1. Curci, G.; Alyuz, U.; Barò, R.; Bianconi, R.; Bieser, J.; Christensen, J.H.; Colette, A.; Farrow, A.; Francis, X.; Jiménez-Guerrero, P.; et al. Modelling black carbon absorption of solar radiation: Combining external and internal mixing assumptions. Atmos. Chem. Phys. Discuss. 2019, 19, 181-204. [CrossRef]

2. Mao, M.; Sun, H.; Zhang, X. Air pollution characteristics and health risks in the Yangtze river economic belt, China during winter. Int. J. Environ. Res. Public Health 2020, 17, 9172. [CrossRef]

3. Jin, S.; Ma, Y.; Zhang, M.; Gong, W.; Lei, L.; Ma, X. Comparation of aerosol optical properties and associated radiative effects of air pollution events between summer and winter: A case study in January and July 2014 over Wuhan, central China. Atmos. Environ. 2019, 218, 117004. [CrossRef]

4. Ma, Y.; Zhang, M.; Jin, S.; Gong, W.; Chen, N.; Chen, Z.; Jin, Y.; Shi, Y. Long-term investigation of aerosol optical and radiative characteristics in a typical megacity of central China during winter haze periods. J. Geophys. Res. 2019, 124, 12093-12106. [CrossRef]

5. Ma, Y.; Fan, R.; Jin, S.; Ma, X.; Zhang, M.; Gong, W.; Liu, B.; Shi, Y.; Zhang, Y.; Li, H. Black carbon over Wuhan, China: Seasonal variations in its optical properties, radiative forcing and contribution to atmospheric aerosols. Remote Sens. 2021, $13,3620$. [CrossRef]

6. Zhang, X.; Rao, R.; Huang, Y.; Mao, M.; Berg, M.J.; Sun, W. Black carbon aerosols in urban central China. J. Quant. Spectrosc. Radiat. Transf. 2015, 150, 3-11. [CrossRef]

7. Bond, T.C.; Doherty, S.J.; Fahey, D.W.; Forster, P.M.; Berntsen, T.; DeAngelo, B.J.; Flanner, M.G.; Ghan, S.; Kaercher, B.; Koch, D.; et al. Bounding the role of black carbon in the climate system: A scientific assessment. J. Geophys. Res. Atmos. 2013, 118, 5380-5552. [CrossRef]

8. Wang, Y.; Ma, P.; Peng, J.; Zhang, R.; Jiang, J.H.; Easter, R.C.; Yung, Y.L. Constraining aging processes of black carbon in the community atmosphere model using environmental chamber measurements. J. Adv. Model. Earth Syst. 2018, 10, $2514-2526$. [CrossRef]

9. Zuberi, B.; Johnson, K.S.; Aleks, G.K.; Molina, L.T.; Molina, M.J.; Laskin, A. Hydrophilic properties of aged soot. Geophys. Res. Lett. 2005, 32, 01807. [CrossRef]

10. Zhang, R.; Khalizov, A.F.; Pagels, J.; Zhang, D.; Xue, H.; McMurry, P.H. Variability in morphology, hygroscopicity, and optical properties of soot aerosols during atmospheric processing. Proc. Natl. Acad. Sci. USA 2008, 105, 10291-10296. [CrossRef] [PubMed]

11. Riemer, N.; West, M.; Zaveri, R.; Easter, R. Estimating black carbon aging time-scales with a particle-resolved aerosol model. J. Aerosol Sci. 2010, 41, 143-158. [CrossRef]

12. He, C.; Li, Q.; Liou, K.-N.; Qi, L.; Tao, S.; Schwarz, J.P. Microphysics-based black carbon aging in a global CTM: Constraints from HIPPO observations and implications for global black carbon budget. Atmos. Chem. Phys. Discuss. 2016, 16, 3077-3098. [CrossRef]

13. Peng, J.; Hu, M.; Guo, S.; Du, Z.; Zheng, J.; Shang, D.; Zamora, M.L.; Zeng, L.; Shao, M.; Wu, Y.-S.; et al. Markedly enhanced absorption and direct radiative forcing of black carbon under polluted urban environments. Proc. Natl. Acad. Sci. USA 2016, 113, 4266-4271. [CrossRef] [PubMed]

14. Wang, X.; Heald, C.L.; Liu, J.; Weber, R.J.; Campuzano-Jost, P.; Jimenez, J.L.; Schwarz, J.P.; Perring, A.E. Exploring the observational constraints on the simulation of brown carbon. Atmos. Chem. Phys. 2018, 18, 635-653. [CrossRef]

15. Moteki, N.; Kondo, Y.; Miyazaki, Y.; Takegawa, N.; Komazaki, Y.; Kurata, G.; Shirai, T.; Blake, D.R.; Miyakawa, T.; Koike, M. Evolution of mixing state of black carbon particles: Aircraft measurements over the western Pacific in March 2004. Geophys. Res. Lett. 2007, 34, 11803. [CrossRef]

16. Shiraiwa, M.; Kondo, Y.; Moteki, N.; Takegawa, N.; Miyazaki, Y.; Blake, D.R. Evolution of mixing state of black carbon in polluted air from Tokyo. Geophys. Res. Lett. 2007, 34, 16803. [CrossRef]

17. Johnson, K.S.; Zuberi, B.; Molina, L.T.; Molina, M.J.; Iedema, M.J.; Cowin, J.P.; Gaspar, D.J.; Wang, C.; Laskin, A. Processing of soot in an urban environment: Case study from the Mexico City Metropolitan Area. Atmos. Chem. Phys. Discuss. $2005,5,3033-3043$. [CrossRef]

18. Kondo, Y.; Matsui, H.; Moteki, N.; Sahu, L.; Takegawa, N.; Kajino, M.; Zhao, Y.; Cubison, M.J.; Jimenez, J.L.; Vay, S.; et al. Emissions of black carbon, organic, and inorganic aerosols from biomass burning in North America and Asia in 2008. J. Geophys. Res. Space Phys. 2011, 116, 08204. [CrossRef] 
19. Khalizov, A.; Cruz-Quinones, M.; Zhang, R. Heterogeneous reaction of $\mathrm{NO}_{2}$ on fresh and coated soot surfaces. J. Phys. Chem. A 2010, 114, 7516-7524. [CrossRef]

20. Zhang, R.; Khalizov, A.; Wang, L.; Hu, M.; Xu, W. Nucleation and growth of nanoparticles in the atmosphere. Chem. Rev. 2012, 112, 1957-2011. [CrossRef]

21. Kirchstetter, T.W.; Thatcher, T.L. Contribution of organic carbon to wood smoke particulate matter absorption of solar radiation. Atmos. Chem. Phys. 2012, 12, 6067-6072. [CrossRef]

22. Zhang, X.; Mao, M.; Chen, H. Characterization of optically effective complex refractive index of black carbon composite aerosols. J. Atmos. Sol.-Terr. Phys. 2020, 198, 105180. [CrossRef]

23. Coz, E.; Leck, C. Morphology and state of mixture of atmospheric soot aggregates during the winter season over Southern Asia-A quantitative approach. Tellus B 2011, 63, 107-116. [CrossRef]

24. Srivastava, R.; Ramachandran, $S$. The mixing state of aerosols over the Indo-Gangetic Plain and its impact on radiative forcing. $Q$. J. R. Meteorol. Soc. 2013, 139, 137-151. [CrossRef]

25. He, C. Radiative properties of atmospheric black carbon (soot) particles with complex structures. In Springer Series in Light Scattering; Kokhanovsky, A., Ed.; Springer: Cham, Switzerland, 2019; Volume 4, pp. 219-254.

26. Kahnert, M.; Kanngiesser, F. Modelling optical properties of atmospheric black carbon aerosols. J. Quant. Spectrosc. Radiat. Transf. 2020, 244, 106849. [CrossRef]

27. Liu, D.; He, C.; Schwarz, J.P.; Wang, X. Lifecycle of light-absorbing carbonaceous aerosols in the atmosphere. NPJ Clim. Atmos. Sci. 2020, 3, 40. [CrossRef]

28. Cappa, C.D.; Onasch, T.B.; Massoli, P.; Worsnop, D.R.; Bates, T.S.; Cross, E.S.; Davidovits, P.; Hakala, J.; Hayden, K.L.; Jobson, B.T.; et al. Radiative absorption enhancements due to the mixing state of atmospheric black carbon. Science 2012, 337, $1078-1081$. [CrossRef]

29. Liu, D.; Whitehead, J.; Alfarra, R.; Reyes-Villegas, E.; Spracklen, D.V.; Reddington, C.; Kong, S.; Williams, P.; Ting, Y.-C.; Haslett, S.; et al. Black-carbon absorption enhancement in the atmosphere determined by particle mixing state. Nat. Geosci. 2017, 10, 184-188. [CrossRef]

30. Chakrabarty, R.K.; Heinson, W.R. Scaling laws for light absorption enhancement due to nonrefractory coating of atmospheric black carbon aerosol. Phys. Rev. Lett. 2018, 121, 218701. [CrossRef]

31. You, R.; Radney, J.; Zachariah, M.R.; Zangmeister, C.D. Measured wavelength-dependent absorption enhancement of internally mixed black carbon with absorbing and nonabsorbing materials. Environ. Sci. Technol. 2016, 50, 7982-7990. [CrossRef]

32. Cui, X.; Wang, X.; Yang, L.; Chen, B.; Chen, J.; Andersson, A.; Gustafsson, Ö. Radiative absorption enhancement from coatings on black carbon aerosols. Sci. Total Environ. 2016, 551-552, 51-56. [CrossRef] [PubMed]

33. Chen, B.; Bai, Z.; Cui, X.; Chen, J.; Andersson, A.; Gustafsson, Ö. Light absorption enhancement of black carbon from urban haze in northern China winter. Environ. Pollut. 2017, 221, 418-426. [CrossRef]

34. Scarnato, B.V.; Vahidinia, S.; Richard, D.T.; Kirchstetter, T.W. Effects of internal mixing and aggregate morphology on optical properties of black carbon using a discrete dipole approximation model. Atmos. Chem. Phys. 2013, 13, 5089-5101. [CrossRef]

35. Dong, J.; Zhao, J.; Liu, L. Morphological effects on the radiative properties of soot aerosols in different internally mixing states with sulfate. J. Quant. Spectrosc. Radiat. Transf. 2015, 165, 43-55. [CrossRef]

36. He, C.; Liou, K.-N.; Takano, Y.; Zhang, R.; Zamora, M.L.; Yang, P.; Li, Q.; Leung, L.R. Variation of the radiative properties during black carbon aging: Theoretical and experimental intercomparison. Atmos. Chem. Phys. Discuss. 2015, 15, 11967-11980. [CrossRef]

37. Zhang, X.; Mao, M.; Yin, Y.; Wang, B. Absorption enhancement of aged black carbon aerosols affected by their microphysics: A numerical investigation. J. Quant. Spectrosc. Radiat. Transf. 2017, 202, 90-97. [CrossRef]

38. Zhang, X.; Mao, M.; Yin, Y.; Wang, B. Numerical investigation on absorption enhancement of black carbon aerosols partially coated with nonabsorbing organics. J. Geophys. Res. Atmos. 2018, 123, 1297-1308. [CrossRef]

39. Cheng, Y.; He, K.-B.; Du, Z.-Y.; Engling, G.; Liu, J.-M.; Ma, Y.-L.; Zheng, M.; Weber, R.J. The characteristics of brown carbon aerosol during winter in Beijing. Atmos. Environ. 2016, 127, 355-364. [CrossRef]

40. Luo, J.; Zhang, Y.; Wang, F.; Zhang, Q. Effects of brown coatings on the absorption enhancement of black carbon: A numerical investigation. Atmos. Chem. Phys. Discuss. 2018, 18, 16897-16914. [CrossRef]

41. China, S.; Mazzoleni, C.; Gorkowski, K.; Aiken, A.; Dubey, M. Morphology and mixing state of individual freshly emitted wildfire carbonaceous particles. Nat. Commun. 2013, 4, 2122. [CrossRef]

42. China, S.; Scarnato, B.; Owen, R.C.; Zhang, B.; Ampadu, M.T.; Kumar, S.; Dzepina, K.; Dziobak, M.P.; Fialho, P.; Perlinger, J.A.; et al. Morphology and mixing state of aged soot particles at a remote marine free troposphere site: Implications for optical properties. Geophys. Res. Lett. 2015, 42, 1243-1250. [CrossRef]

43. Li, W.; Sun, J.; Xu, L.; Shi, Z.; Riemer, N.; Sun, Y.; Fu, P.; Zhang, J.; Lin, Y.; Wang, X.; et al. A conceptual framework for mixing structures in individual aerosol particles. J. Geophys. Res. Atmos. 2016, 121, 13784-13798. [CrossRef]

44. Sorensen, C.M. Light scattering by fractal aggregates: A review. Aerosol Sci. Technol. 2001, 35, 648-687. [CrossRef]

45. Zhang, Y.; Zhang, Q.; Cheng, Y.; Su, H.; Kecorius, S.; Wang, Z.; Wu, Z.; Hu, M.; Zhu, T.; Wiedensohler, A.; et al. Measuring the morphology and density of internally mixed black carbon with SP2 and VTDMA: New insight into the absorption enhancement of black carbon in the atmosphere. Atmos. Meas. Tech. 2016, 9, 1833-1843. [CrossRef]

46. Liu, D.; Taylor, J.W.; Young, D.E.; Flynn, M.J.; Coe, H.; Allan, J.D. The effect of complex black carbon microphysics on the determination of the optical properties of brown carbon. Geophys. Res. Lett. 2015, 42, 613-619. [CrossRef] 
47. Skorupski, K.; Mroczka, J.; Wriedt, T.; Riefler, N. A fast and accurate implementation of tunable algorithms used for generation of fractal-like aggregate models. Phys. A Stat. Mech. Appl. 2014, 404, 106-117. [CrossRef]

48. Zhang, X.; Mao, M.; Yin, Y.; Tang, S. The absorption Ångstrom exponent of black carbon with brown coatings: Effects of aerosol microphysics and parameterization. Atmos. Chem. Phys. Discuss. 2020, 20, 9701-9711. [CrossRef]

49. Mackowski, D. A general superposition solution for electromagnetic scattering by multiple spherical domains of optically active media. J. Quant. Spectrosc. Radiat. Transf. 2014, 133, 264-270. [CrossRef]

50. Yu, F.; Luo, G. Simulation of particle size distribution with a global aerosol model: Contribution of nucleation to aerosol and CCN number concentrations. Atmos. Chem. Phys. Discuss. 2009, 9, 7691-7710. [CrossRef]

51. Zhang, K.; O’Donnell, D.; Kazil, J.; Stier, P.; Kinne, S.; Lohmann, U.; Ferrachat, S.; Croft, B.; Quaas, J.; Wan, H.; et al. The global aerosol-climate model ECHAM-HAM, version 2: Sensitivity to improvements in process representations. Atmos. Chem. Phys. Discuss. 2012, 12, 8911-8949. [CrossRef]

52. Zhang, X.; Mao, M.; Chen, H.; Yin, Y.; Tang, S. Lensing effect of black carbon with brown coatings: Dominant microphysics and parameterization. J. Geophys. Res. Atmos. 2021, 126, e2020JD033549. [CrossRef]

53. Zhang, X.; Mao, M.; Yin, Y. Optically effective complex refractive index of coated black carbon aerosols: From numerical aspects. Atmos. Chem. Phys. Discuss. 2019, 19, 7507-7518. [CrossRef]

54. Kirchstetter, T.W.; Novakov, T.; Hobbs, P.V. Evidence that the spectral dependence of light absorption by aerosols is affected by organic carbon. J. Geophys. Res. Space Phys. 2004, 109, 21208. [CrossRef]

55. Chakrabarty, R.K.; Moosmüller, H.; Chen, L.-W.A.; Lewis, K.; Arnott, W.P.; Mazzoleni, C.; Dubey, M.K.; Wold, C.E.; Hao, W.M.; Kreidenweis, S.M. Brown carbon in tar balls from smoldering biomass combustion. Atmos. Chem. Phys. Discuss. 2010, 10, 6363-6370. [CrossRef]

56. Bond, T.; Bergstrom, R.W. Light absorption by carbonaceous particles: An investigative review. Aerosol Sci. Technol. 2006, 40, 27-67. [CrossRef] 